\title{
DIVERSIDAD GENÉTICA EN RESTOS HUMANOS ARQUEOLÓGI- COS DEL SITIO EL DIQUECITO (COSTA SUR, LAGUNA MAR CHIQUITA, PROVINCIA DE CÓRDOBA)
}

\author{
Rodrigo Nores*, Mariana Fabra, Angelina García y Darío A. Demarchi
}

Instituto de Antropología de Córdoba (CONICET-UNC). Facultad de Filosofía y Humanidades. Universidad Nacional de Córdoba. Córdoba. Argentina

\section{PALABRAS CLAVE arqueogenética; ADNmitocondrial; continuidad poblacional}

\begin{abstract}
RESUMEN En este trabajo presentamos los resultados del análisis de haplogrupos y de secuencias de la región hipervariable I del ADN mitocondrial (RHV-I) en restos humanos del sitio El Diquecito, en la región sur de la laguna Mar Chiquita, provincia de Córdoba, con antigüedades comprendidas entre $2562 \pm 47$ y $537 \pm 57{ }^{14} \mathrm{C}$ años AP. De los 14 individuos analizados, 11 pudieron ser secuenciados $\mathrm{y}$ asignados con certeza a un linaje mitocondrial de origen continental americano, que coincidió con el determinado previamente por APLP. Entre las 7 secuencias correspondientes al haplogrupo $\mathrm{C} 1$ se reconocen 2 haplotipos diferentes, aunque solo una no presenta el haplotipo nodal. Entre las 4 secuencias pertenecientes al haplogrupo D1 se distinguen 3 haplotipos diferentes: uno corresponde al
\end{abstract}

haplotipo nodal, otro al subhaplogrupo D1j y los dos restantes al subhaplogrupo D1g. El análisis de las secuencias del ADN mitocondrial permitió, en algunos casos, inferir el origen geográfico del aporte genético ocurrido en la región de la laguna Mar Chiquita y, en otros, identificar linajes que se habrían originado en la región central de Argentina. Si bien las conclusiones que pueden formularse a partir del estudio de un solo sitio son limitadas, el estudio de la diversidad de linajes mitocondriales de los pobladores antiguos de la costa sur de la laguna Mar Chiquita representa un nuevo aporte para comprender los procesos microevolutivos que sufrieron las poblaciones originarias del centro de Argentina. Rev Arg Antrop Biol 19(1), 2017. doi:10.17139/raab.2017.0019.01.05

KEY WORDS archaeogenetics; mitochondrial DNA; population continuity

ABSTRACT We present the results of analysis of haplogroups and sequences of mtDNA hypervariable region I (HVR-I) in human remains from the site El Diquecito, in the southern shore of Mar Chiquita lagoon, in Córdoba, dated between $2562 \pm 47$ and $537 \pm 57{ }^{14} \mathrm{C}$ yr BP. Out of the 14 individuals analyzed, 11 could be sequenced and assigned to one Native American mitochondrial lineage, which matched the one previously determined by APLP. The 7 haplogroup $\mathrm{C} 1$ sequences correspond to 2 different haplotypes, although only one did not present the nodal haplotype. The $4 \mathrm{D} 1$ haplogroup sequences belong to 3 different haplotypes: one corresponds to the nodal haplotype, one to the subhaplogroup $\mathrm{D} 1 \mathrm{j}$, and the remaining two present the subhaplogroup D1g. Analysis of mitochondrial DNA sequences allowed, in some cases, to infer the geographic origin of the genetic contribution occurred in the region of Mar Chiquita lagoon, and in other cases, to identify lineages originated in the central region of Argentina. While the conclusions that can be drawn from the analysis of one single site are limited, the study of the mitochondrial lineages of the ancient inhabitants of the south shore of Mar Chiquita lagoon represents a new contribution to understanding the microevolutionary processes undergone by the indigenous populations of central Argentina. Rev Arg Antrop Biol 19(1), 2017. doi:10.17139/ raab.2017.0019.01.05
De acuerdo a la evidencia arqueológica, la región central de Argentina ha estado habitada por humanos al menos durante los últimos diez a doce mil años (Rivero y Roldán, 2005; Laguens et al., 2007). La Laguna Mar Chiquita, ubicada en la región noreste de la provincia de Córdoba, al noroeste de la llanura pampeana de Argentina (Fig. 1), es considerada una de las áreas de ocupación más temprana, principalmente a partir del hallazgo del Hombre Fósil de Miramar, cuya datación y coexistencia con megafauna lo ubican en el Holoceno temprano (Montes, 1960). Esta laguna conforma el receptáculo final de un sistema endorreico de aproximadamente $127000 \mathrm{~km}^{2}$ integrado por las cuencas de los ríos Suquía, Xanaes y Salí-Dulce y por pequeños sistemas dispersos (Piovano et al., 2006). En su extremo sudoeste, la laguna presenta otra laguna satelital llamada Laguna del Plata, donde desemboca actualmente el río Suquía. En su porción distal,

\footnotetext{
*Correspondencia a: Rodrigo Nores. Museo de Antropología. Av. Hipólito Yrigoyen 174. 5000 Córdoba. Argentina. e-mail: rodrigonores@hotmail.com
}

Financiamiento: SECyT (UNC) y ANPCyT (PICT 2012, $\mathrm{N}^{\circ} 0711$; PICT 2013, N²028)

Recibido 22 Octubre 2015; aceptado 5 Julio 2016

doi:10.17139/raab.2017.0019.01.05 
el río Suquía presenta dos brazos denominados Nuevo y Viejo, entre los que se ubica el sitio de estudio El Diquecito (Fig. 1).

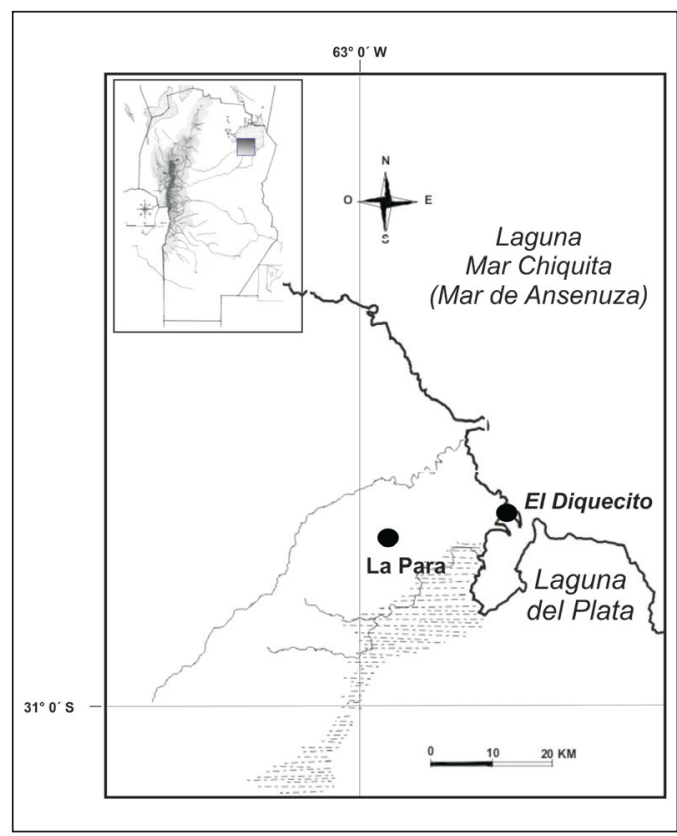

Fig. 1. Mapa de la costa sudoeste de la Laguna Mar Chiquita, Provincia de Córdoba, Argentina. Se indica la ubicación del sitio arqueológico de estudio El Diquecito y de la localidad de La Para.

La Laguna Mar Chiquita es un cuerpo de agua salina, poco profundo, que ha tenido una extensión variable, fluctuando entre $1800 \mathrm{~km}^{2}$ en épocas de bajo nivel hasta más $6000 \mathrm{~km}^{2}$ (según registros de la crecida ocurrida a finales de la década de 1970). El registro paleoclimático indica para el Holoceno medio condiciones de extrema sequía y niveles de agua muy bajos, cuyo punto extremo ha sido datado en $c a .4700$ años antes del presente (AP). Esta fase fue seguida por períodos de mayor humedad, señalados por niveles altos entre 1500 y 1100 años AP, asignados a la Anomalía Climática Medieval, con una magnitud equivalente a los desarrollados durante el final del Siglo XX. La aparición en superficie de restos arqueológicos, tales como fragmentos de cerámica, estructuras circulares destinadas al almacenamiento y estructuras de inhumación en diferentes topografías de los sectores costeros, permiten analizar la variación de la ocupación humana en relación con la variabilidad hidroló- gica de la laguna (Piovano et al., 2009), y sugieren que en las terrazas altas se habría producido el asentamiento de los grupos humanos que habitaron la región hasta momentos del contacto hispano-indígena (Fabra et al., 2008, 2014a).

En base a la cantidad y cronología de los sitios arqueológicos relevados hasta el momento en la Provincia de Córdoba, se estima que hacia finales del Holoceno tardío, entre 1500 y 1000 años AP, se habría producido un aumento en la densidad demográfica, coincidente con la aparición de una agricultura incipiente. Evidencias obtenidas a partir del estudio de rasgos morfogeométricos (Fabra y Demarchi, 2013) y moleculares (Nores et al., 2011) sugieren que este aumento demográfico podría estar asociado a un aporte inmigratorio desde el Noroeste argentino hacia la región serrana, ubicada al oeste de la provincia de Córdoba, y desde el sur y el litoral hacia las poblaciones de la llanura extraserrana del este de la provincia, las cuales de acuerdo al registro bioarqueológico, parecen haber estado particularmente concentradas sobre la margen sudoeste de la Laguna Mar Chiquita (Fabra, 2013; Fabra et al., 2014a, 2015). También la información arqueomalacológica refuerza la idea de contactos entre poblaciones asentadas en la costa sur de esta laguna con poblaciones del Litoral argentino, dado que se han encontrado artefactos formatizados realizados sobre valvas pertenecientes a la almeja Diplodon parallelopipedon, que vive en la cuenca del Paraná, y no ha sido registrada previamente para Córdoba (Gordillo y Fabra, 2014). Asimismo, el hallazgo en dos entierros del sitio El Diquecito de valvas de moluscos pertenecientes a la especie Anodontites trapesialis, que vive en ríos y lagos de agua dulce y por lo tanto, no habría habitado la laguna Mar Chiquita, refuerza la idea de contactos con poblaciones que habitaron el norte de la región pampeana (Fabra et al., 2012, 2014a).

En los últimos años se han producido numerosos hallazgos de restos óseos humanos en contextos de inhumación, puestos al descubierto por el continuo avance y retroceso de las aguas de la laguna (Fabra et al., 2008, 2014a). Estos procesos de aumento y descenso en los niveles de costa han generado un proceso de erosión continua que ha repercutido en la conservación de los sitios arqueológicos, situación que ha requerido la realización de rescates arqueológicos 
para la recuperación sistemática de restos óseos humanos en esta región costera.

De particular interés es el sitio El Diquecito, ubicado sobre la margen sudoeste de la Laguna Mar Chiquita (Fig. 1), de donde se recuperaron un total de 14 individuos. Fue excavado en tres campañas arqueológicas, realizadas entre los años 2008 y 2010, por solicitud de particulares y voluntarios del Museo Histórico Municipal de la localidad de La Para, en el marco del Programa "Arqueología Pública: patrimonio arqueológico y derechos culturales en el Noreste de la Provincia de Córdoba". La datación radiocarbónica de 12 de estos restos sugiere una ocupación del sitio en dos períodos, separados por una posible desocupación de aproximadamente 700 años, que podría ser interpretada tanto como producto de un despoblamiento del área como de procesos post-depositacionales que hayan limitado la visibilidad de las ocupaciones. El período temprano estaría comprendido aproximadamente entre 2600 y $1900{ }^{14} \mathrm{C}$ años AP y el período tardío entre 1200 y $500{ }^{14} \mathrm{C}$ años AP. En función de la evidencia arqueológica, se trataría de un sitio residencial y no de un área exclusiva destinada a la inhumación, ya que los entierros no se encuentran diferenciados espacialmente de las áreas domésticas o destinadas al almacenamiento. El análisis de bioindicadores dentales, de isótopos estables de ${ }^{13} \mathrm{C}$ y de marcadores de actividad física sugieren diferencias en los estilos de vida de las comunidades que habitaron esta región en ambos momentos, sugiriendo a) un desmejoramiento en los niveles generales de salud en momentos tardíos, b) una mayor diversidad en la dieta, para las poblaciones más antiguas, y c) un cambio en el tipo o intensidad de las actividades físicas realizadas hacían finales del Holoceno (Fabra et al., 2013).

El estudio de marcadores genéticos de herencia uniparental ha sido particularmente útil para la reconstrucción de la historia evolutiva de las poblaciones humanas, sobre todo cuando es posible investigar la variabilidad temporal a través del estudio de los restos antiguos, gracias al empleo de cada vez más eficientes técnicas moleculares. Sin embargo, no son muchos los estudios sobre ADN antiguo en poblaciones prehispánicas de Argentina (para una revisión, ver Postillone et al., 2014), entre los cuales sólo 5 publicaciones incluyen secuencias mitocon- driales de la región control (García-Bour et al., 2004; Wilson et al., 2007; Carnese et al., 2010; Mendisco et al., 2011, 2014).

En este trabajo presentamos los resultados del secuenciamiento de la Región Hipervariable I del ADN mitocondrial (RHV-I) de restos humanos encontrados en el sitio El Diquecito, y el análisis temporal de la variación biológica entre muestras antiguas y actuales para evaluar si hubo continuidad biológica a lo largo del tiempo o reemplazo poblacional, con el objeto de aportar a la comprensión de los procesos microevolutivos que se sucedieron durante 2600 años de ocupación humana en la región sudoeste de la Laguna Mar Chiquita.

\section{MATERIAL Y MÉTODOS}

\section{El sitio}

El sitio El Diquecito se encuentra a $15 \mathrm{~km}$ de la localidad de La Para, en la costa sudoeste de la Laguna Mar Chiquita, a $30^{\circ} 53^{\prime}$ latitud sur y $62^{\circ} 50^{\prime}$ longitud oeste (Fig. 1). Se trata de un sitio al aire libre, definido a partir de la aparición en superficie de restos arqueológicos (fragmentos de cerámica, material lítico, estructuras circulares o botijas y restos óseos humanos) dispersos a lo largo de $500 \mathrm{~m}$ lineales de la costa actual de la laguna (Fig. 2). Los restos óseos se encontraban semienterrados, presentando una alta variabilidad en cuanto a las modalidades de entierro, y en algunos casos afectados por la erosión hídrica propia del avance y retroceso del agua de la laguna, que ha eliminado entre $0,50 \mathrm{~m}$ y $0,90 \mathrm{~m}$ de la capa sedimentaria (Fig. 3). Detalles sobre los contextos arqueológicos, prácticas mortuorias, dataciones radiocarbónicas e información isotópica, así como análisis de diversos bioindicadores dentales, pueden encontrarse en Fabra et al. (2008, 2013).

\section{La muestra}

La extracción de ADN se realizó a partir de muestras óseas (falanges de mano y pie) o dentales de 14 restos humanos de origen arqueológico, conservados en el Museo de Antropología (FFyH, UNC). Se definieron dos submuestras temporales para investigar si era posible observar alguna tendencia temporal en la variación 


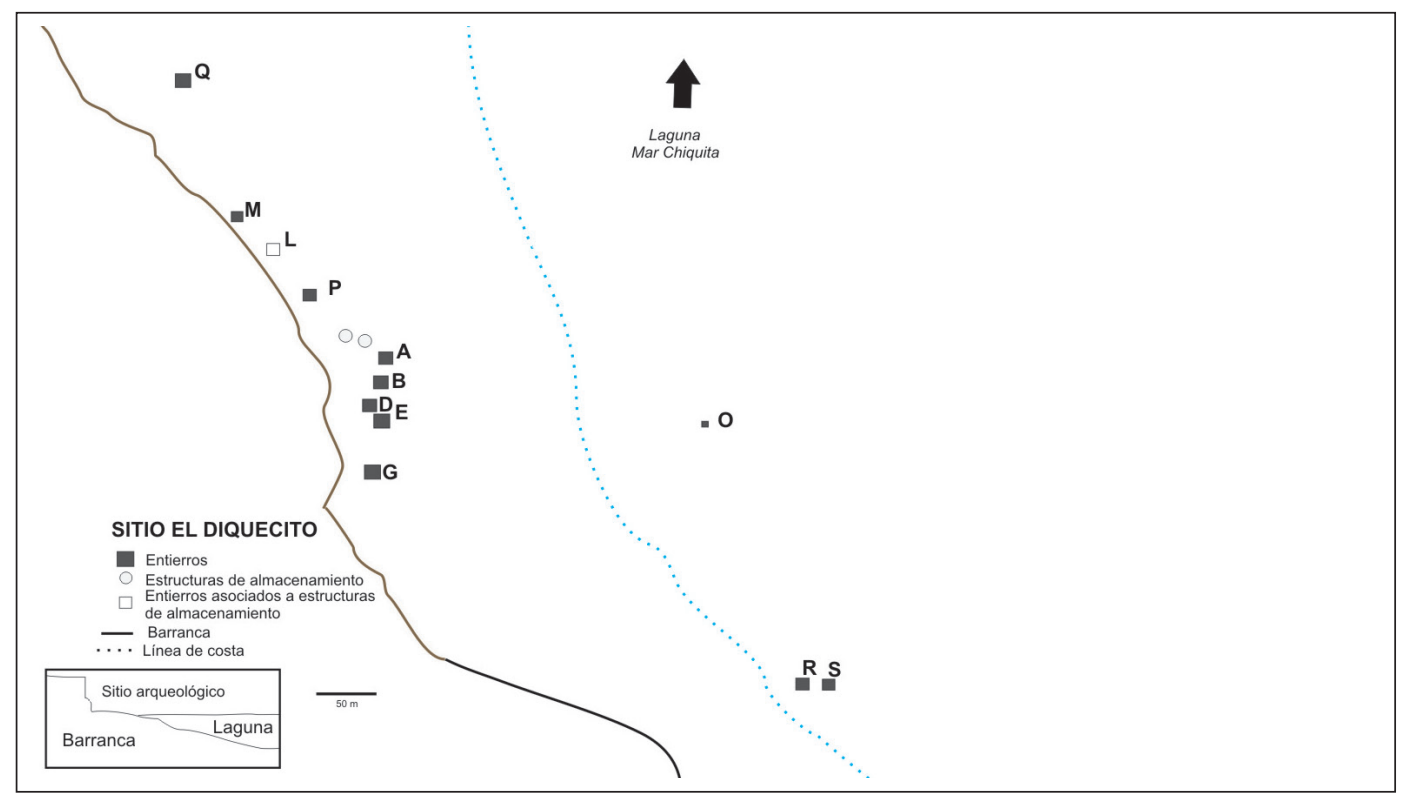

Fig. 2. Mapa del sitio El Diquecito, sobre la costa de la Laguna Mar Chiquita. Se indica la línea actual de costa y la ubicación de los entierros y estructuras de almacenamiento. En el recuadro se observa un corte transversal del sitio arqueológico y del área de playa y barrancas.

genética o, por el contrario, la distribución de haplogrupos permanecía estable a lo largo del tiempo. La submuestra pre-1200 AP (n=5), comprende a los individuos dentro de un rango de antigüedad de $2562 \pm 47$ a $1911 \pm 59{ }^{14} \mathrm{C}$ años $\mathrm{AP}$, mientras que la submuestra post-1200 $\mathrm{AP}(\mathrm{n}=7)$ incluye a los datados en el rango $1192 \pm 40-537 \pm 57{ }^{14} \mathrm{C}$ años AP, separadas por un período intermedio de setecientos años de posible desocupación de la región, para el cual no se registran hallazgos. Dos individuos no fueron incluidos en estas submuestras ya que aún no han sido datados.

Para comparar la distribución de frecuencias de la muestra estudiada frente a la que presenta la población contemporánea que habita la región, se utilizó la información de frecuencias de haplogrupos mitocondriales de los habitantes con linajes maternos nativos de La Para, que representan el 78\% de la población (García y Demarchi, 2009).

\section{Análisis bioantropológico}

Los resultados del análisis bioantropológico se presentaron en Fabra et al. (2008, 2013). Brevemente, la determinación del sexo y la estimación de edad de cada uno de los individuos fueron realizadas a partir de los estándares propuestos por Buikstra y Ubelaker (1994). Para la determinación del sexo se consideraron principalmente las características de la pelvis y en caso de estar ausente o muy fragmentada, la morfología craneal. Para la estimación de la edad se examinó y asignó cada caso a las categorías de infante, niño, adolescente o adulto $\mathrm{y}$, posteriormente, se seleccionó el criterio apropiado para la definición de la edad dentro de cada una de estas categorías. Se tuvieron en cuenta aquellos cambios que se producen en la pelvis y el grado de fusión de las epífisis en los huesos largos.

En la Tabla 1 se presenta la información bioantropológica de los 14 individuos analizados en el presente trabajo.

\section{Análisis de ADN antiguo}

\section{Precauciones para evitar la contaminación}

Diversas precauciones fueron tomadas para minimizar el riesgo de contaminación de las muestras a lo largo de todo el estudio, desde la recolección hasta el trabajo en el laboratorio de 


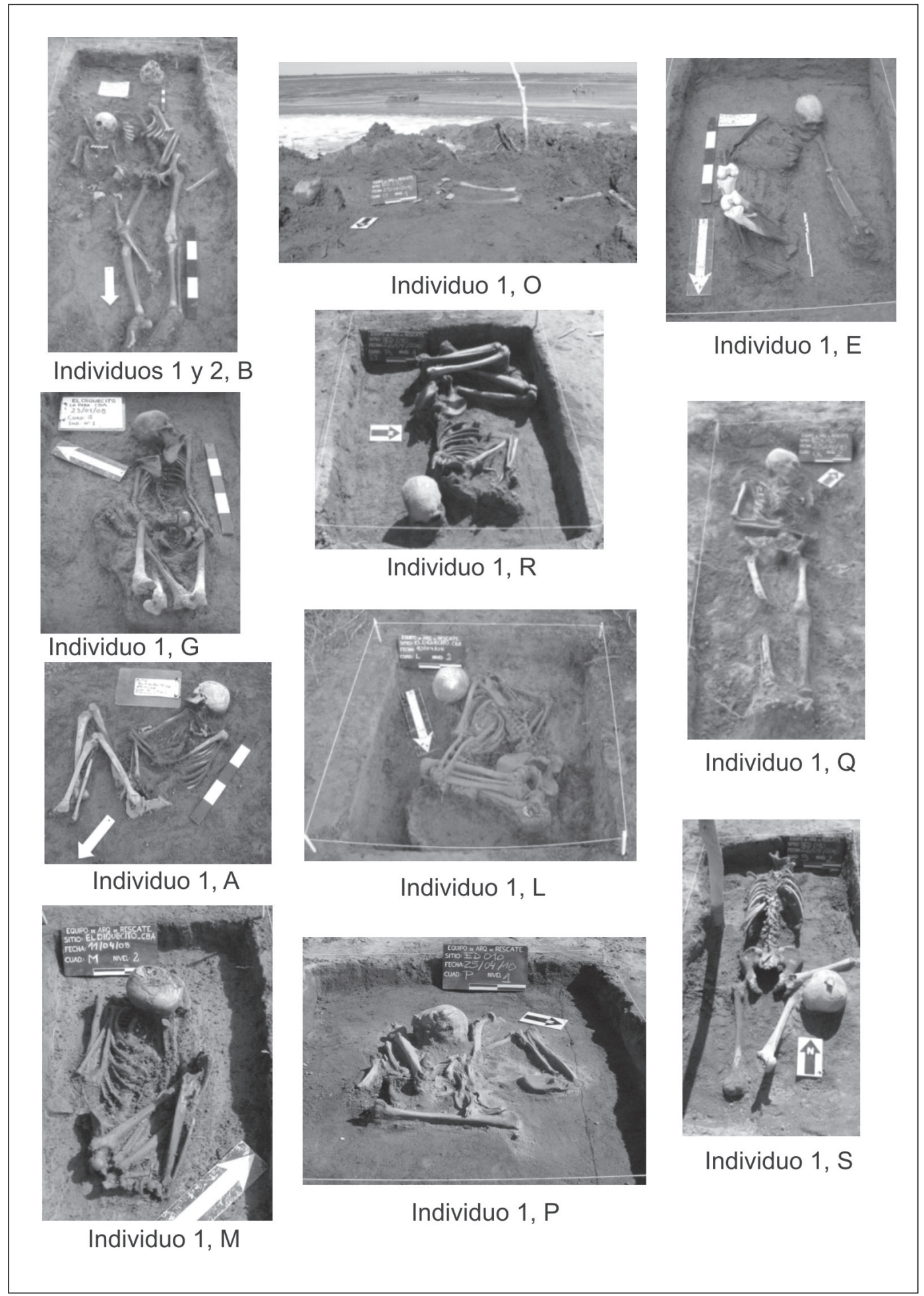

Fig. 3. Detalle de los individuos analizados en este trabajo. Se puede observar la variabilidad en la modalidad de los enterramientos, así como la conservación diferencial de los mismos. 


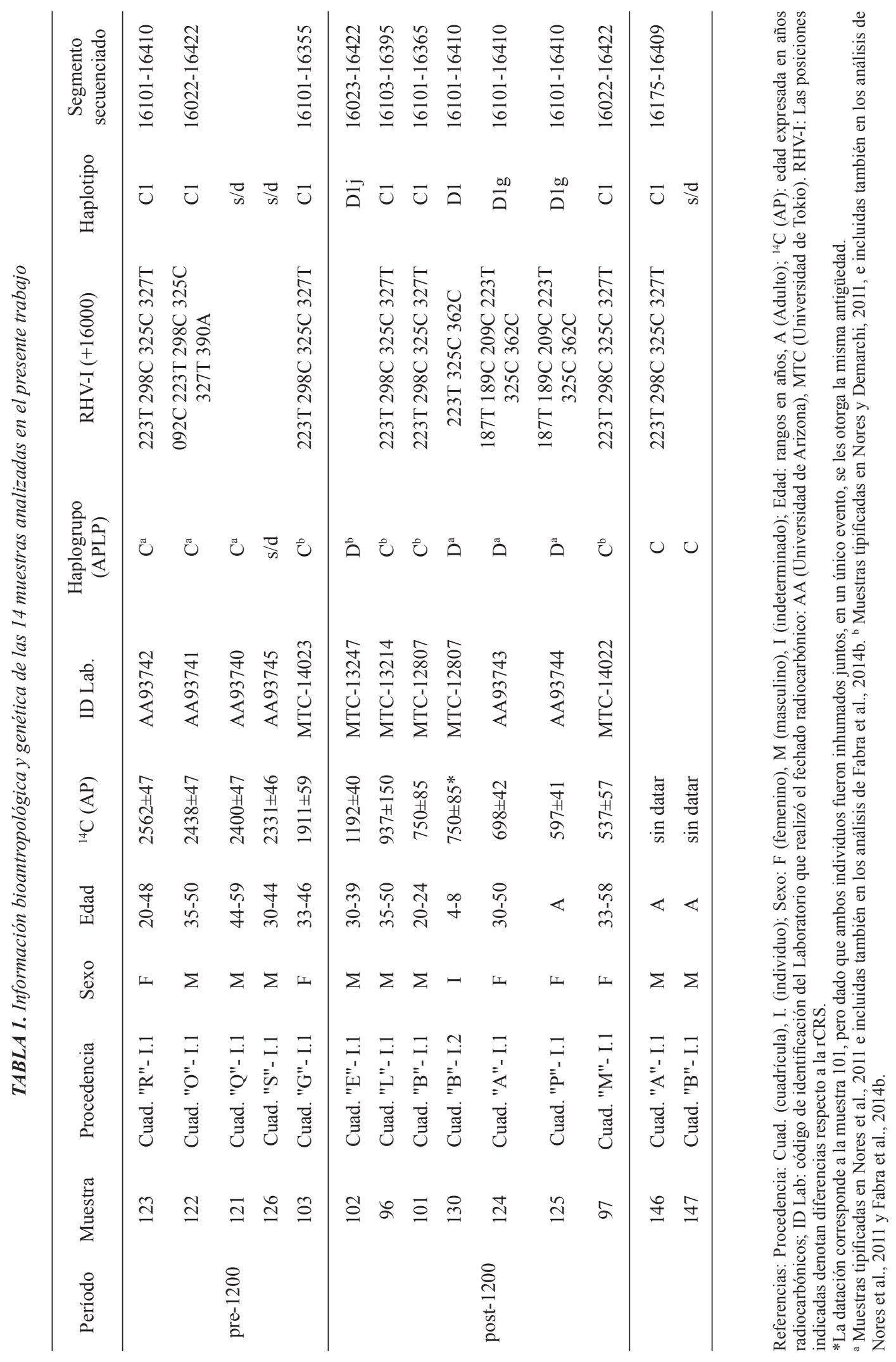


extracción y tipificación del ADN. En general, se siguieron las recomendaciones presentadas por Pääbo et al., (2004) y descritas por Nores y Demarchi (2011).

\section{Extracción de $A D N$}

Se siguió un protocolo de extracción basado en la descalcificación y digestión de las muestras óseas o dentarias. En primer término, las muestras fueron sumergidas en hipoclorito de sodio al 6\% durante 5-15 minutos, luego lavadas repetidamente con agua destilada y secadas en estufa. A continuación, las muestras fueron pulverizadas con torno dental a baja velocidad y el polvillo obtenido $(0,3-0,5 \mathrm{~g})$ fue decalcificado en un microtubo de $2 \mathrm{ml}$ en presencia de $1 \mathrm{ml}$ de una solución $0,5 \mathrm{M}$ EDTA $(\mathrm{pH} 8,0)$ y $1 \mathrm{mg}$ de proteinasa $\mathrm{K}$ a $56^{\circ} \mathrm{C}$ durante 24 a 48 horas con agitación. El ADN fue extraído del sobrenadante obtenido después de una centrifugación a $5000 \mathrm{~g}$ por 5 minutos usando el kit Wizard SV PCR Clean-Up System (Promega), que se basa en la afinidad del ADN por la sílice en presencia de altas concentraciones salinas.

\section{Determinación de haplogrupos mitocondriales}

Los polimorfismos del ADN mitocondrial diagnóstico de los haplogrupos $\mathrm{A}, \mathrm{C}$ y $\mathrm{D}$ fueron tipificados por PCR-APLPs (Amplified product-length polymorphisms), mientras que la determinación del haplogrupo B fue realizada mediante PCR directa (Adachi et al., 2004, 2009; Shinoda et al., 2006; Nores y Demarchi, 2011). La visualización de los productos de amplificación se realizó mediante geles nativos de acrilamida: bisacrilamida (19:1) al 8\%, teñidos por 30min con GelStar 1:10000 (Lonza), en transiluminador de luz UV. Se utilizaron los iniciadores y protocolos descriptos en Nores y Demarchi (2011).

\section{Secuenciamiento de la Región Hipervariable I del ADN mitocondrial (RHV-I)}

El secuenciamiento de la RHV-I se realizó siguiendo el protocolo descrito en Lee et al. (2006). Debido a la fragmentación del ADN en las muestras antiguas, se amplificaron dos fragmentos solapantes menores a 221 pares de bases (pb) de la RHV-I del ADN mitocondrial, entre las posiciones 16101 y 16410 , utilizando los iniciadores descriptos en Adachi et al. (2009). Para el caso de las muestras más degradadas se amplificaron tres fragmentos menores a 160 $\mathrm{pb}$, comprendidos entre los nucleótidos 16022 y 16422 (Raff et al., 2010). Los productos de PCR se enviaron a Macrogen (Seúl, Corea) para su purificación y posterior secuenciamiento de ambas cadenas de ADN.

Las secuencias obtenidas fueron corregidas manualmente y alineadas con la Secuencia de Referencia revisada de Cambridge (rCRS) (Andrews et al., 1999), usando el programa Sequencher versión 5.3 (Gene Codes Corporation). Posteriormente, fueron asignadas a los haplogrupos correspondientes utilizando la base de datos HaploGrep 2.0 (Kloss-Brandstaetter et al., 2010; http://haplogrep.uibk.ac.at/), que se basa en la versión más actualizada de Phylotree (versión 17; van Oven y Kayser, 2009). Los segmentos secuenciados comprendieron una longitud de entre 254 y 400 pb (Tabla 1).

\section{Análisis de datos}

Las diferencias en la distribución de frecuencias (entre las submuestras pre y post-1200 AP, y entre la muestra antigua y la contemporánea) se analizaron a través del Test Exacto (Raymond y Rousset, 1995) con el programa Arlequin 3.5 (Excoffier y Lischer, 2010).

\section{RESULTADOS}

Las precauciones tomadas en la recolección y el procesamiento de las muestras y durante el análisis en el laboratorio fueron exitosas, ya que no se observaron productos de amplificación en ninguno de los controles negativos (de PCR o blanco de extracción). Tampoco se encontraron evidencias de contaminación con ADN exógeno en las secuencias de la RHV-I obtenidas.

\section{Análisis de haplogrupos mitocondriales por APLP}

De los 14 individuos recuperados en el sitio El Diquecito, 11 ya habían sido tipificados para linajes mitocondriales por APLP (Nores y Demarchi, 2011; Nores et al., 2011) y 2 se determinaron en este estudio. Sólo un individuo de $2331 \pm 46$ años AP no pudo ser tipificado, ya que no se obtuvieron productos de amplificación por 
PCR (dado por la ausencia o degradación avanzada del ADN mitocondrial, o por la presencia de inhibidores de la reacción de PCR). De las 13 muestras positivas, 4 corresponden al período pre-1200 AP y 7 a la etapa post- $1200 \mathrm{AP}$, mientras que 2 de las muestras no poseen datación radiocarbónica. La totalidad de los individuos pertenecientes a la muestra pre-1200 AP y los dos individuos no datados presentan el haplogrupo $\mathrm{C}$, mientras que en la muestra post-1200 AP encontramos 3 individuos con el haplogrupo C y 4 con el haplogrupo D (Tabla 1). No se encontraron en el sitio individuos con los haplogrupos $\mathrm{A}$ o B; sin embargo, estas ausencias podrían estar dadas por un error muestral (tamaño de muestra insuficiente), ya que el haplogrupo A está presente en restos arqueológicos humanos procedentes de sitios cercanos a El Diquecito, como Marull, Laguna de la Sal, La Para y Miramar, y el haplogrupo B fue hallado en un individuo de Colonia Müller (Nores y Demarchi, 2011; Nores et al., 2011; Nores et al., 2014).

La distribución de haplogrupos entre ambos períodos, separados por una brecha temporal de setecientos años, muestra algunas diferencias evidentes, como son la exclusividad del haplogrupo $\mathrm{C}$ en las muestras más antiguas y el predominio del haplogrupo $\mathrm{D}$ en el período post-1200 AP, presente en 4 de 7 muestras. Sin embargo, de acuerdo al Test Exacto, estas diferencias no llegan a ser estadísticamente significativas $(p=0,191 \pm 0,003)$.

Por otra parte, la comparación de la muestra arqueológica total con la población actual de $\mathrm{La}$ Para (García y Demarchi, 2009), en la que prevalece el haplogrupo $C(0,460)$, seguido por el D $(0,320)$, tampoco muestra diferencias significativas en la distribución de haplogrupos maternos nativos $(p=0,361 \pm 0,007)$. La alta frecuencia de los linajes C y D y la ausencia o muy baja frecuencia de los haplogrupos A y B en ambas muestras sugieren continuidad poblacional en el tiempo.

\section{Secuenciamiento de la RHV-I del ADN mitocondrial}

En la tabla 1 se indican los sitios polimórficos de la RHV-I que difieren de la rCRS de los 11 individuos secuenciados en este estudio. El análisis de la secuencia de la región control del ADN mitocondrial permite definir con cer- teza la pertenencia de cada muestra a un linaje mitocondrial de origen continental americano, incluido en los grandes grupos determinados previamente por APLP. Siete muestras presentan el haplogrupo $\mathrm{C} 1$ y las 4 restantes el linaje D1. Entre las 7 secuencias pertenecientes al haplogrupo $\mathrm{C} 1$ se reconocen 2 haplotipos diferentes: el haplotipo nodal, representado por 6 individuos, y un haplotipo definido por la presencia de dos sitios mutados adicionales a la secuencia nodal (T16092C y G16390A), en la muestra 122. Considerando los iniciadores utilizados, no fue posible determinar en las 6 muestras con el haplotipo nodal la pertenencia a alguno de los 3 subhaplogrupos $\mathrm{C} 1$ americanos $(\mathrm{C} 1 \mathrm{~b}, \mathrm{C} 1 \mathrm{c}$ y C1d), cuyos sitios diagnóstico están por fuera del rango de lectura obtenido.

Por su parte, entre las 4 secuencias pertenecientes al haplogrupo D1 se distinguen 3 haplotipos diferentes: una corresponde al haplotipo nodal (muestra 130), otra al subhaplogrupo D1j (muestra 102) y los dos restantes al subhaplogrupo D1g (muestras 124 y 125).

\section{DISCUSIÓN}

La diferencia en la distribución de haplogrupos mitocondriales entre la muestra de la población antigua de El Diquecito y la que presentan los habitantes con linajes americanos de La Para, localidad ubicada a $15 \mathrm{~km}$ de distancia, no es significativa. Si bien la significación estadística en estos análisis estaría condicionada por el pequeño tamaño de la muestra arqueológica, se observa una tendencia que sugiere la continuidad biológica de la población antigua de la Laguna Mar Chiquita con la población actual del noreste de la provincia de Córdoba a lo largo del tiempo. Esta tendencia es concordante con resultados previos encontrados mediante la determinación por APLP de haplogrupos mitocondriales en muestras arqueológicas de la provincia de Córdoba, que incluyen a la mayoría de las muestras analizadas en el presente trabajo (Tabla 1). En un primer estudio (Nores et al., 2011) comparamos la distribución de frecuencias a nivel geográfico (Sierras vs. Llanura) y temporal (pre-1200 AP vs. post-1200 AP vs. población actual). Al contrastar los perfiles genéticos de la población arqueológica dividida por regiones geográficas con los linajes maternos 
americanos de la población contemporánea de toda la provincia de Córdoba, observamos que la distribución de frecuencias de la población actual es similar a la de la submuestra Llanura $(n=22)$ y difiere significativamente de la encontrada en la submuestra Sierras. Posteriormente, en otro estudio (Fabra et al., 2014b) analizamos 38 muestras arqueológicas de la región de la Laguna Mar Chiquita a nivel de haplogrupos mitocondriales y comparamos con poblaciones actuales de la zona, encontrando el mismo escenario evolutivo de continuidad poblacional.

La similitud estadística encontrada entre las muestras arqueológicas previas y posteriores al año 1200 AP estaría dada posiblemente por el pequeño tamaño muestral $(n=4$ y 7 , respectivamente). La alta incidencia del haplogrupo $\mathrm{D}$ en las muestras más recientes, y la exclusividad del linaje $\mathrm{C}$ entre las más antiguas dan cuenta de una tendencia a la discontinuidad biológica que ya fue planteada con anterioridad para las poblaciones arqueológicas de la provincia de Córdoba. En este sentido, la evidencia morfológica craneofacial (Fabra y Demarchi, 2013) y particularmente, molecular (Nores y Demarchi, 2011; Nores et al., 2011) sugieren la existencia de una historia poblacional compleja, según la cual la distribución de haplogrupos en individuos procedentes de sitios arqueológicos que habitaron la región serrana y las llanuras de la provincia de Córdoba, particularmente la región sur de la costa de la Laguna Mar Chiquita, son significativamente diferentes, pero sólo entre las muestras posteriores al 1280 AP (8 de las 10 muestras de sierras y llanura que presentan dataciones anteriores a esa fecha presentan el haplogrupo C). La ausencia del linaje B entre las muestras serranas más antiguas y la preponderancia del mismo entre las más modernas $(47,6 \%)$ podría deberse a un aporte migratorio hacia la zona serrana desde poblaciones con alta incidencia del haplogrupo $\mathrm{B}$, tales como las chaqueñas (Wichí y Toba; Demarchi et al., 2001), y las andinas: puneños y atacameños (Dipierri et al., 1998; Merriwether et al. 1995) o la población antigua de Pampa Grande, Salta (Carnese et al., 2010). Por otra parte, la relativamente alta representación de los haplogrupos A y D en la llanura (22,7\% y $31,8 \%$, respectivamente) que son menos frecuentes en las sierras $(11,5 \%$ en ambos casos), sugiere flujo génico desde el este y el noreste, de donde provienen los grupos guaraníes, que se caracterizan por una alta incidencia del haplogrupo A (Altuna y Demarchi, 2003) y desde el sur, dada la alta frecuencia de los haplogrupos C y D que tienen los grupos de Patagonia y Tierra del Fuego (Fox, 1996; Moraga et al., 2000; Bravi, 2004). La presencia de un único individuo de linaje $\mathrm{B}$ entre 38 muestras arqueológicas de la llanura (Fabra et al., 2014b) refuerza la hipótesis de este aporte migratorio diferencial entre las sierras y la llanura.

Mediante el secuenciamiento de la región control del ADN mitocondrial de 11 de las 14 muestras analizadas se obtuvo un grado de definición de linajes y sublinajes que nos permitió, en algunos casos, inferir el origen geográfico del aporte genético ocurrido en la región de la Laguna Mar Chiquita y en otros, identificar linajes que se habrían originado en la región central de Argentina. En lo que respecta al haplogrupo C1, sólo la muestra 122 , de $2438 \pm 47$ años de antigüedad, se diferenció de la secuencia nodal, ya que presenta dos sitios mutados adicionales (T16092C y G16390A) que han sido previamente descriptos sólo en muestras del centrooeste del país (García, 2011; Motti, 2012; Pauro et al., 2013). Sin embargo, la combinación en un mismo individuo de ambos sitios, conformando el motivo $\mathrm{C} 1+16092 \mathrm{C}+16390 \mathrm{~A}$ no ha sido descripta hasta el presente, por lo que podría tratarse de un linaje extinto o presente en muy baja frecuencia en la población actual.

Por otro lado, el análisis de las 4 secuencias del haplogrupo D1 reveló la presencia de un individuo con el haplotipo nodal, otro perteneciente al linaje Dij y dos individuos portadores del linaje D1g. El linaje D1j, definido por Bodner et al. (2012), se encuentra ampliamente distribuido y con altas frecuencias relativas, que llegan hasta el $45 \%$ de los linajes nativos, en poblaciones del centro y oeste de Argentina (Tamm et al., 2007; García et al., 2012; Motti, 2012). La presencia de las mutaciones $\mathrm{C} 16242 \mathrm{~T}$ y T16311C, características del linaje D1j, en el individuo 102, de $1092 \pm 40$ años AP y en otro individuo de $4525 \pm 20$ años AP de las costas de la Laguna Mar Chiquita (García et al., 2012; Nores et al., 2014), es evidencia de una gran profundidad temporal de este linaje en la región y a una escala geográfica mayor, refuerza la hipótesis de un origen local en las Sierras Pam- 
peanas para este subhaplogrupo, como sugieren García et al. (2012) en base a su distribución en poblaciones contemporáneas. Por otro lado, el subhaplogrupo D1g se define por la presencia de la mutación C16187T y es característico de poblaciones antiguas y actuales de la Patagonia (García-Bour et al., 2004; Moraga et al., 2010; de Saint Pierre et al., 2012). Este linaje está ampliamente representado en la población contemporánea de las provincias de Córdoba, San Luis y en menor medida, Santiago del Estero (García, 2011, Pauro et al., 2013, Motti, 2012) y está presente en las muestras arqueológicas 124 y 125 , de $698 \pm 42$ y $597 \pm 41{ }^{14} \mathrm{C}$ años AP, respectivamente. Es interesante destacar que este linaje D1g también se encontró en una muestra de la región serrana de Córdoba, de $387 \pm 41{ }^{14} \mathrm{C}$ años de antigüedad (Nores et al., 2014), estando ausente en las muestras de mayor temporalidad. Por lo tanto, a pesar de estar ampliamente distribuido en la población contemporánea del centro-oeste de Argentina, su presencia en muestras de individuos que vivieron en tiempos relativamente próximos sería resultado del contacto reciente entre poblaciones de la Patagonia y de esta región, pudiendo tal vez ser atribuida a los movimientos migratorios posteriores al 1200 AP que generaron la diferenciación biológica de las poblaciones tempranas y tardías.

La ausencia en El Diquecito de muestras pertenecientes a los haplogrupos A2 y B2, así como la imposibilidad de diferenciar los sublinajes $\mathrm{C} 1 \mathrm{~b}, \mathrm{C} 1 \mathrm{c}$ y $\mathrm{C} 1 \mathrm{~d}$ entre las 6 muestras con el haplotipo nodal C1 limitó nuestras posibilidades de comparación con secuencias mitocondriales obtenidas de otros sitios arqueológicas de Argentina, tales como Pampa Grande, Salta (Carnese et al., 2007), en donde predominan los linajes B2; Los Amarillos, Jujuy (Mendisco et al., 2011), en donde prevalecen los linajes A2; y Quebrada de Humahuaca, Jujuy (Mendisco et al., 2014), con presencia mayoritaria de linajes A2, B2 y C1b. Resulta entonces fundamental para continuar con el estudio de la variación genética de las poblaciones antiguas de la región de la Laguna Mar Chiquita y, en un contexto regional mayor, del área central de Argentina, aumentar el tamaño muestral y por ende, el rango temporal y geográfico de la muestra. Es preciso, además, refinar el análisis de secuencias ampliando el rango de lectura de la región control del ADN mitocondrial e incluir, si es necesario, la tipificación de sitios diagnóstico en la región codificante, para poder definir con más precisión linajes y sublinajes que nos permitan hacer inferencias sobre origen geográfico y temporalidad de la variabilidad biológica.

Más allá de las limitaciones encontradas, la presentación de los primeros resultados basados en el análisis de secuencias mitocondriales sobre la variación genética temporal de la población antigua de la costa sur de la Laguna Mar Chiquita constituye un aporte válido y un estímulo para continuar en esta línea de investigación, que proporciona una herramienta importante para entender los procesos microevolutivos que sufrieron las poblaciones humanas antiguas de esta región.

\section{AGRADECIMIENTOS}

Los autores agradecen al Museo de Antropología (FFyH, UNC) y al Museo Histórico Municipal de La Para, por permitir el análisis de los restos humanos bajo su cuidado. A su vez, agradecen a la Agencia Nacional de Promoción Científica y Tecnológica y a la Secretaría de Ciencia y Tecnología de la Universidad Nacional de Córdoba por el financiamiento otorgado para este trabajo. Rodrigo Nores, Mariana Fabra, Angelina García y Darío Demarchi son investigadores del CONICET.

\section{Nota}

${ }^{1}$ Programa “Arqueología Pública: patrimonio arqueológico y derechos culturales en el Noreste de la Provincia de Córdoba" (resolución HCD 267/11), dirigido por Mariana Fabra y Mariela Zabala, dependiente de la Secretaría de Extensión Universitaria y del Museo de Antropología (FFyH, UNC), y del convenio firmado entre el Museo de Antropología, el Equipo Argentino de Antropología Forense y el Poder Judicial de la Provincia de Córdoba para la recuperación de restos óseos humanos, tanto en contextos arqueológicos como forenses.

\section{LITERATURA CITADA}

Adachi N, Shinoda K, Umetsu K, Matsumura H. 2009. Mitochondrial DNA analysis of Jomon skeletons from the Funadomari site, Hokkaido, and its implication for the origins of Native American. Am J Phys Anthropol 138:255-265. doi:10.1002/ajpa.20923 
Adachi N, Umetsu K, Takigawa W, Sakaue K. 2004. Phylogenetic analysis of the human ancient mitochondrial DNA. J Archaeol Sci 31:1339-1348.

Altuna ME, Demarchi DA. 2003. Haplogrupos mitocondriales en los Mbyá-Guaraní de la Provincia de Misiones. Libro de Resúmenes de las Sextas Jornadas Nacionales de Antropología Biológica. San Fernando del Valle de Catamarca: Asociación de Antropología Biológica Argentina. p 115 .

Andrews RM, Kubacka I, Chinnery PF, Lightowlers RN, Turnbull DM, Howell N. 1999. Reanalysis and revision of the Cambridge reference sequence for human mitochondrial DNA. Nature Genet 23:147.

Bodner M, Perego UA, Huber G, Fendt L, Röck AW, Zimmermann B, Olivieri A, Gómez-Carballa A et al. 2012. Rapid coastal spread of first Americans: novel insights from South America's Southern Cone mitochondrial genomes. Genome Res 22:811-20. doi: 10.1101/ gr.131722.111.

Bravi CM. 2004. Análisis de linajes maternos en poblaciones indígenas americanas. Tesis Doctoral inédita. Facultad de Ciencias Naturales y Museo. Universidad Nacional de la Plata.

Buikstra J, Ubelaker D editores. 1994. Standards for data collection from human skeletal remains. Field Museum of Natural History. Arkansas Archaeological Survey Research Series N 44.

Carnese FR., Mendisco F, Keyser C, Dejean CB, Dugoujon JM, Bravi CM, Ludes B, Crubézy E. 2010. Paleogenetical study of pre-columbian samples from Pampa Grande (Salta, Argentina). Am J Phys Anthropol 141:452-62. doi: 10.1002/ajpa.21165

de Saint Pierre M, Bravi CM, Motti JM, Fuku N, Tanaka M, Llop E, Bonatto SL, Moraga M. 2012. An alternative model for the early peopling of southern South America revealed by analyses of three mitochondrial DNA haplogroups. PLoS ONE 7:e43486. doi:10.1371/journal. pone. 0043486

Demarchi DA, Panzetta-Dutari GM, Motran CC, Basualdo MA, Marcellino AJ. 2001. Mitochondrial DNA haplogroups in Amerindian populations from the Gran Chaco. Am J Phys Anthropol 115:199-203.

Dipierri JE, Alfaro E, Martinez-Marignac VL, Bailliet G, Bravi CM, Cejas S, Bianchi NO. 1998. Paternal directional mating in two Amerindian subpopulations located at different altitude in the northwest of Argentina. Hum Biol 70:1001-1010.

Excoffier L, Lischer HEL. 2010. Arlequin suite ver 3.5: a new series of programs to perform population genetics analyses under Linux and Windows. Mol Ecol Resour 10:564-567. doi: 10.1111/j.1755-0998.2010.02847.x

Fabra M, Demarchi DA. 2013. Análisis morfogeométrico aplicado al estudio de los patrones espaciales y temporales de variación morfológica craneofacial en poblaciones del centro de Argentina. Revista Cuadernos del Instituto Nacional de Pensamiento Latinoamericano, Series Especiales. $1^{\circ}$ Congreso Internacional de Arqueología de la Cuenca del Plata 1:87-101. http://ppct.caicyt. gov.ar/index.php/cinapl-se/article/view/3943/pdf

Fabra M, González CV, Robin S. 2015. Evidencias de violencia interpersonal en poblaciones del piedemonte y las llanuras de Córdoba (Argentina) a finales del Holoceno tardío. Runa 36:5-27.

Fabra M, Gordillo S, Piovano EL. 2012. Arqueomalacología en las costas de Ansenuza: análisis de una almeja nacarífera (Anodontites trapesialis) hallada en contexto funerario del sitio El Diquecito (Laguna Mar Chiquita, Córdoba). Arqueología 18:257-266.
Fabra M, Nores R, Salega S, González CV. Entre las sierras y el mar: Investigaciones bioarqueológicas en el Noroeste de la Región Pampeana (costa sur de la Laguna Mar Chiquita, Córdoba, Argentina). 2014. En: Luna L, Aranda C, Suby J, editores. Avances recientes de la bioarqueología latinoamericana. Buenos Aires: Grupo de Investigación en Bioarqueología. 205-230.

Fabra M, Salega MS, González CV, Tavarone A. 2014. Apuntes sobre la vida en el mar de Ansenuza: una mirada desde el sitio El Diquecito (Laguna Mar Chiquita, Provincia de Córdoba, Argentina). Libro de resúmenes II Congreso Internacional de Arqueología de la Cuenca del Plata. San José de Mayo: Facultad de Humanidades y Ciencias de la Educación, Universidad de la República. p 239.

Fabra M, Salega S, González C, Smeding R, Pautassi E. 2008. Arqueología de rescate en la costa sur de la Laguna Mar Chiquita: sitio arqueológico El Diquecito. Memorias del Pueblo: Revista del Museo Histórico Municipal "La Para" 8:37-46.

Fabra M, Salega S, González CV, Tavarone A. 2013, Investigaciones bioarquelógicas en El sitio El Diquecito (Laguna Mar Chiquita, Provincia de Córdoba). Libro de resúmenes de las XI Jornadas Nacionales de Antropología Biológica. Buenos Aires: Asociación de Antropología Biológica Argentina. p 148.

Fabra M, Salega S, González CV, Tavarone A. 2014. Lo que el agua nos dejó: investigaciones bioarqueológicas en la costa sur de la Laguna Mar Chiquita (Córdoba, Argentina). Jangwa Pana 13:51-64.

Fabra M. 2013. Variación epigenética craneofacial y dinámica evolutiva de poblaciones humanas del norte de la región pampeana durante el holoceno tardío. Revista Cuadernos del Instituto Nacional de Pensamiento Latinoamericano, Series Especiales. $1^{\circ}$ Congreso Internacional de Arqueología de la Cuenca del Plata 1:74-86. http://ppct.caicyt.gov.ar/index.php/cinapl-se/article/ view/3944/pdf

Fox CL. 1996. Mitochondrial DNA haplogroups in four tribes from Tierra del Fuego-Patagonia: inferences about the peopling of the Americas. Hum Biol 68:855-871.

García A, Demarchi DA. 2009. Incidence and distribution of Native American mtDNA haplogroups in Central Argentina. Hum Biol 81:59-69. doi: 10.3378/027.081.0105

García A, Pauro M, Nores R, Bravi CM, Demarchi DA. 2012. Phylogeography of mitochondrial haplogroup D1: an early spread of subhaplogroup D1j from Central Argentina. Am J Phys Anthropol 149:583-590. doi: 10.1002/ajpa.22174

García A. 2011. Historia evolutiva de las poblaciones originarias del actual territorio de la provincia de Córdoba: evidencias moleculares. Tesis Doctoral inédita. Facultad de Ciencias Exactas, Física y Naturales. Universidad Nacional de Córdoba.

García-Bour J, Pérez-Pérez A, Álvarez S, Fernández E, López-Parra AM, Arroyo-Pardo E, Turbón D. 2004. Early population differentiation in extinct aborigines from Tierra del Fuego-Patagonia: ancient mtDNA sequence and Y-chromosome STR characterization. Am J Phys Anthropol 123:361-370. doi:10.1002/ajpa.10337

Gordillo S, Fabra M. 2014. El uso de moluscos y caracoles por parte de poblaciones prehispánicas que habitaron el Mar de Ansenuza en el norte cordobés. Memorias del Pueblo Digital: Revista del Museo Histórico Municipal La Para 1:5-17.

Kloss-Brandstaetter A, Pacher D, Schoenherr S, Weissensteiner H, Binna R, Specht G, Kronenberg F. 2011. HaploGrep: a fast and reliable algorithm for automatic classification 
of mitochondrial DNA haplogroups. Hum Mutat 32:2532. doi:10.1002/humu.21382

Laguens A, Demarchi DA, Fabra M. 2007. Un estudio bioantropológico y arqueológico de la colonización humana del sector sur de las Sierras Pampeanas. En: Olmedo E, Ribero F, compiladores. Debates actuales en Arqueología y Etnohistoria. Río Cuarto: Editorial Universidad Nacional de Río IV. p 119-134.

Mendisco F, Keyser C, Hollard C, Seldes V, Nielsen AE, Crubézy E, Ludes B. 2011. Application of the IPLEXTM Gold SNP genotyping method for the analysis of Amerindian ancient DNA samples: benefits for ancient population studies. Electrophoresis 32:1-8. doi: 10.1002/elps.201000483

Mendisco F, Keyser C, Seldes V, Rivolta C, Mercolli P, Cruz P, Nielsen AE, Crubézy E, Ludes B. 2014. Genetic diversity of a late prehispanic group of the Quebrada de Humahuaca, Northwestern Argentina. Ann Hum Genet 78:367-380. doi:10.1111/ahg. 12075

Merriwether DA, Rothhammer F, Ferrell RE. 1995. Distribution of the four founding lineage haplotype in native Americans suggest a single wave of migration for the New World. Am J Phys Anthropol 98:411-30. doi:10.1002/ajpa.1330980404

Montes A. 1960. El hombre fósil de Miramar (Córdoba). Revista de la Facultad de Ciencias Exactas, Físicas y Naturales 21(1 y 2).

Moraga M, de Saint Pierre M, Torres F, Ríos J. 2010. Vínculos de parentesco por vía materna entre los últimos descendientes de la etnia Kawésqar y algunos entierros en los canales patagónicos: evidencia desde el estudio de linajes mitocondriales. Magallania 38:103-114.

Moraga M, Rocco P, Miquel JF, Nervi F, Llop E, Chakraborty R, Rothhammer F, Carvallo P. 2000. Mitochondrial DNA polymorphisms in Chilean aboriginal populations: implications for the peopling of the southern cone of the continent. Am J Phys Anthropol 113:1929. doi:10.1002/1096-8644(200009)113:1<19::AIDAJPA3 $>3.0 . \mathrm{CO} ; 2-\mathrm{X}$

Motti JMB. 2012. Caracterización de linajes maternos en la población actual del noroeste y centro-oeste argentinos. Tesis doctoral inédita. Facultad de Ciencias Naturales y Museo. Universidad Nacional de La Plata.

Nores R, Demarchi DA. 2011. Análisis de haplogrupos mitocondriales en restos humanos de sitios arqueológicos de la provincia de Córdoba. Rev Arg Antrop Biol 13:43-54.

Nores R, Fabra M, Demarchi DA. 2011. Variación temporal y espacial en poblaciones prehispánicas de Córdoba. Análisis de ADN antiguo. Revista del Museo de Antropología 4:187-194.

Nores R, García A, Pauro M, Bravi C, Demarchi DA. 2014. Estructura genética y filogeografía de los antiguos habitantes de la provincia de Córdoba, Argentina. Análisis de linajes maternos. Libro de resúmenes del XIII Congreso Latinoamericano de Antropología Biológica. Santiago de Chile: Asociación Latinoamericana de Antropología Biológica. p 64 .

Pääbo S, Poinar H, Serre D, Jaenicke-Despres V, Hebler J, Rohland N, Kuch M, Krause J Vigilant L, Hofrei- ter M. 2004. Genetic analyses from ancient DNA. Ann Rev Genet 38:645-679. doi:10.1146/annurev.genet.37.110801.143214

Pauro M, García A, Nores R, Demarchi DA. 2013. Analysis of uniparental lineages in two villages of Santiago del Estero, Argentina, seat of "Pueblos de Indios" in colonial times. Hum Biol 85:699-719. doi: $10.3378 / 027.085 .0504$

Piovano E, Zanor G, Ariztegui D. 2006. Marco geológico general. En: Bucher E, editor. Bañados del río Dulce y Laguna Mar Chiquita. Córdoba: Academia Nacional de Ciencias. p 29-35.

Piovano LE, Ariztegui D, Córdoba F, Cioccale M, Sylvestre F. 2009. Hydrological variability in South America below the tropic of Capricorn (Pampas and Patagonia, Argentina) during the last $13.0 \mathrm{ka}$. En: Vimeux F, Sylvestre F, Khodri M, editores. Past climate variability in South America and surrounding regions. Developments in Paleoenvironmental Research 14:323-351.

Postillone MB, Crespo CM, Russo MG, Cardozo DG. 2014. Distribución de haplogrupos mitocondriales amerindios en muestras arqueológicas de Sudamérica. En: Castro Esnal A, Funes ML, Grosso M, Kuperszmit N Murgo A, Romero G, editoras. Entre pasados y presentes IV. Estudios Contemporáneos en Ciencias Antropológicas. Ciudad Autónoma de Buenos Aires: Editorial AINA. 347-362. doi: 10.13140/2.1.5127.3289

Raff J, Tackney J, O'Rourke DH. 2010. South from Alaska: a pilot aDNA study of genetic history on the Alaska peninsula and the Eastern Aleutians. Hum Biol 82:677693. doi: $10.3378 / 027.082 .0510$

Raymond M, Rousset F. 1995. An exact test for population differentiation. Evolution 49:1280-1283.

Rivero D, Roldán F. 2005. Initial peopling of the Córdoba Mountains, Argentina: first evidence from El Alto 3. Current Research in the Pleistocene 22:33-35.

Shinoda K, Adachi N, Guillen S, Shimada I. 2006. Mitochondrial DNA Analysis of Ancient Peruvian Highlanders. Am J Phys Anthropol 131:98-107. doi:10.1002/ ajpa. 20408

Tamm E, Kivisild T, Reidla M, Metspalu M, Smith DG, Mulligan CJ, Bravi CM, Rickards O, Martinez-Labarga C, Khusnutdinova EK, Fedorova SA, Golubenko MV, Stepanov VA, Gubina MA, Zhadanov SI, Ossipova LP, Damba L, Voevoda MI, Dipierri JE, Villems R, Malhi RS. et al. 2007. Beringian standstill and spread of native American founders. PLoS ONE 2:e829. doi:10.1371/ journal.pone.0000829

van Oven M, Kayser M. 2009. Updated comprehensive phylogenetic tree of global human mitochondrial DNA variation. Hum Mutat 30:E386-E394. doi:10.1002/ humu.20921

Wilson AS, Taylor T, Ceruti MC, Chavez JA, Reinhard J, Grimes V, Meier-Augenstein W, Cartmell L, Stern B, Richards MP, Worobey M, Barnes I, Gilbert MT. 2007. Stable isotope and DNA evidence for ritual sequences in Inca child sacrifice. Proc Natl Acad Sci USA 104:16456-16461. doi:10.1073/pnas.0704276104 